\title{
Erratum to: The 5 As team intervention: bridging the knowledge gap in obesity management among primary care practitioners
}

Ayodele A. Ogunleye ${ }^{1,2^{*}}$, Adedayo Osunlana ${ }^{1}$, Jodie Asselin ${ }^{1,2}$, Andrew Cave ${ }^{2}$, Arya Mitra Sharma ${ }^{1}$ and Denise Lynn Campbell-Scherer ${ }^{2}$

\section{Erratum to: BMC Res Notes (2015) 8:810 DOI 10.1186/s13104-015-1685-8}

Unfortunately, the original version of this article [1] contained an error. The author's name, 'Ayodele A. Ogunleye' did not include the author's middle initial. This has been corrected in the original article and can also be found correctly in the author list above.

\section{Author details}

${ }_{1}^{1}$ Department of Medicine, Obesity Research and Management, Li Ka Shing Center for Health Research Innovation, University of Alberta, Edmonton, AB T6G 2E1, Canada. ${ }^{2}$ Department of Family Medicine, University of Alberta, 6-10 University Terrace, Edmonton, AB T6G 2T4, Canada.

The online version of the original article can be found under doi:10.1186/s13104-015-1685-8.

Received: 10 February 2016 Accepted: 12 February 2016

Published online: 14 March 2016

\section{Reference}

1. Ogunleye AA, et al. The 5 As team intervention: bridging the knowledge gap in obesity management among primary care practitioners. BMC Res Notes. 2015;8:810.

\footnotetext{
*Correspondence: aogunley@ualberta.ca

2 Department of Family Medicine, University of Alberta, 6-10 University

Terrace, Edmonton, AB T6G 2T4, Canada

Full list of author information is available at the end of the article
} 